\title{
Multidrug Resistant Acinetobacter baumannii: Resistance by Any Other Name Would Still be Hard to Treat
}

\author{
David A. Butler ${ }^{1} \cdot$ Mark Biagi $^{1} \cdot$ Xing Tan $^{1} \cdot$ Samah Qasmieh $^{1} \cdot$ Zackery P. Bulman $^{1} \cdot$ Eric Wenzler $^{1}$
}

Published online: 16 November 2019

(C) Springer Science+Business Media, LLC, part of Springer Nature 2019

\begin{abstract}
Purpose of Review Acinetobacter baumannii (AB) is an infamous nosocomial pathogen with a seemingly limitless capacity for antimicrobial resistance, leading to few treatment options and poor clinical outcomes. The debatably low pathogenicity and virulence of $\mathrm{AB}$ are juxtaposed by its exceptionally high rate of infection-related mortality, likely due to delays in time to effective antimicrobial therapy secondary to its predilection for resistance to first-line agents. Recent studies of $\mathrm{AB}$ and its infections have led to a burgeoning understanding of this critical microbial threat and provided clinicians with new ammunition for which to target this elusive pathogen. This review will provide an update on the virulence, resistance, diagnosis, and treatment of multidrug resistant (MDR) AB.

Recent Findings Advances in bacterial genomics have led to a deeper understanding of the unique mechanisms of resistance often present in MDR AB and how they may be exploited by new antimicrobials or optimized combinations of existing agents. Further, improvements in rapid diagnostic tests (RDTs) and their more pervasive use in combination with antimicrobial stewardship interventions have allowed for more rapid diagnosis of $\mathrm{AB}$ and decreases in time to effective therapy. Unfortunately, there remains a paucity of high-quality clinical data for which to inform the optimal treatment of MDR AB infections. In fact, recently completed studies have failed to identify a combination regimen that is consistently superior to monotherapy, despite the benefits demonstrated in vitro. Encouragingly, new and updated guidelines offer strategies for the treatment of MDR AB and may help to harmonize the use of high toxicity agents such as the polymyxins. Finally, new antimicrobial agents such as eravacycline and cefiderocol have promising in vitro activity against MDR AB but their place in therapy for these infections remains to be determined.

Summary Notwithstanding available clinical trial data, polymyxin-based combination therapies with either a carbapenem, minocycline, or eravacycline remain the treatment of choice for MDR, particularly carbapenem-resistant, AB. Incorporating antimicrobial stewardship intervention with RDTs relevant to MDR AB can help avoid potentially toxic combination therapies and catalyze the most important modifiable risk factor for mortality - time to effective therapy. Further research efforts into pharmacokinetic/ pharmacodynamic-based dose optimization and clinical outcomes data for MDR AB continue to be desperately needed.
\end{abstract}

Keywords Acinetobacter baumannii $\cdot$ Resistance $\cdot$ Rapid diagnostics $\cdot$ Combination therapy $\cdot$ Polymyxins $\cdot$ Tetracyclines

\section{Introduction}

Despite the current renaissance in antimicrobial research and development, Acinetobacter baumannii (AB) remains the

Zackery Bulman and Eric Wenzler contributed equally to this work.

This article is part of the Topical Collection on Antimicrobial Development and Drug Resistance

Eric Wenzler

wenzler@uic.edu

1 Department of Pharmacy Practice, College of Pharmacy, University of Illinois at Chicago, 833 South Wood Street, Room 164 (M/C 886), Chicago, IL 60612, USA most important unmet medical need among resistant Gramnegative pathogens. The inability to optimally diagnose and manage $\mathrm{AB}$ infections in a timely manner, particularly those due to resistant phenotypes, stems from its complex genus, the repertoire of unique intrinsic and acquired resistance mechanisms, the lack of routine use of appropriate rapid diagnostic tests (RDTs), a limited number of effective treatment options, and the longstanding debate regarding its true virulence and pathogenicity [1]. For years, there has been significant challenge in differentiating the species within the A. baumanniicalcoaceticus ( $\mathrm{ABC}$ ) complex, which includes $\mathrm{AB}$, A. calcoaceticus, A. nosocomialis, and A. pittii, with $\mathrm{AB}$ being the most clinically relevant and virulent species. Additionally, owing to the many possible resistant phenotypes of $\mathrm{AB}$, the 
nomenclature for referring to $\mathrm{AB}$ is often inconsistent and clinically confusing. For example, multidrug resistant (MDR) AB [2] may or may not qualify as difficult-to-treat (DTR) [3•], and the most commonly encountered phenotype - carbapenem-resistant $\mathrm{AB}(\mathrm{CRAB})$ - may qualify as both or neither. Although these inconsistencies in naming conventions throughout research and clinical practice likely further complicate the understanding of this challenging pathogen, antimicrobial resistant AB (MDR, DTR, and/or CRAB) poses a significant public health threat and is responsible for excess morbidity, mortality, and healthcare costs regardless of how it is named. Fortunately, advances in our understanding of its mechanisms of resistance, progresses in antimicrobial pharmacokinetics/pharmacodynamics (PK/PD), improvements in identification of $\mathrm{AB}$ and its resistance mechanisms, the development of novel antimicrobial agents, and new clinical data informing the optimal therapy for $\mathrm{AB}$ will continue to help turn the tide against this enigmatic pathogen.

\section{Mechanisms of Resistance}

The management of $\mathrm{AB}$ infections is particularly complicated due to this pathogen's multiple intrinsic and acquired mechanisms of resistance including $\beta$-lactamases, aminoglycosidemodifying enzymes, efflux pumps, permeability defects, and target site modifications. AB often simultaneously co-harbor many resistance mechanisms, which may eliminate the activity of multiple, and sometimes all, antibiotic classes. Thus, it is critical that empiric and definitive antimicrobial therapy for $\mathrm{AB}$ infections is guided by an understanding of potential resistance mechanisms and susceptibility trends. The susceptibility rates of various agents against $\mathrm{ABC}$ complex are displayed in Table 1.

\section{$\beta$-Lactams}

$\beta$-Lactam resistance in $\mathrm{AB}$ is primarily mediated by the presence of $\beta$-lactamases, decreased permeability due to modifications in the outer membrane, alterations in penicillinbinding proteins (PBP), and efflux pumps [6]. Carbapenems are an important therapeutic option for $\mathrm{AB}$ due to widespread resistance to penicillins and cephalosporins. However, (CRAB) have emerged as a major problem in the USA and worldwide [10-12]. From 2009-2013, 2915/6507 (44.8\%) $\mathrm{AB}$ isolates originating from 206 acute care hospitals across the USA were carbapenem-resistant [13]. AB is capable of possessing typical Ambler class A $\beta$-lactamases capable of hydrolyzing penicillins and cephalosporins (TEM, SHV, CTX-M, SCO, PER, and VEB) and also less commonly encountered carbapenemases such as GES-5, GES-14, and various KPC-type enzymes [14-17]. Although relatively rare at this time, $\mathrm{AB}$ isolates producing Ambler class $\mathrm{B}$ metallo- $\beta$ - lactamases (MBLs) (i.e., IMP, VIM, and NDM) have also been reported [18] and are particularly worrisome due to their ability to hydrolyze all $\beta$-lactams except for aztreonam [19]. Finally, the most problematic groups of $\beta$-lactamases among resistant $\mathrm{AB}$ are the chromosomally encoded Ambler class $\mathrm{C}$ and acquired class D enzymes. Acinetobacter-derived $\underline{\mathrm{c}-}$ ephalosporinase (ADC), an Ambler class C AmpC-type cephalosporinase, contributes to the resistance of penicillins, cephalosporins, and aztreonam, but not carbapenems [20]. The Ambler class D $\beta$-lactamases are composed of various oxacillinases (OXA), including subgroups of plasmidmediated OXAs with carbapenemase activity such as OXA23, OXA-24, OXA-40, OXA-51, and OXA-58 [20, 21]. Specifically, OXA-23 is a globally disseminated carbapenemase; this is highly prevalent among CRAB [22] and can be used to predict carbapenem susceptibility via genotypic rapid diagnostic tests, as discussed below [23]. Additionally, although sulbactam has intrinsic activity against Acinetobacter spp. and may retain activity against some CRAB isolates, resistance is widespread globally as it is susceptible to hydrolysis by many of the intrinsic and acquired $\beta$ lactamases carried in clinical AB strains, such as TEM, ADC, and OXA-23 [24-26•, 24-29].

\section{Polymyxins}

Historically considered agents of last resort, the polymyxins, have emerged as important agents in the management of $\mathrm{AB}$ infections due to extensive resistance to other antimicrobial classes. Although $>90 \%$ of AB in the USA are susceptible to the polymyxins, they can infrequently be impacted by various mechanisms of resistance, the most common of which are structural changes to the target site lipid A. First, spontaneous mutations occurring in the lipid A biosynthesis genes (IpxA, IpxC, and IpxD) lead to complete loss of lipid $\mathrm{A}$, resulting in high-level polymyxin resistance [30]. Second, mutations in the $\operatorname{pmrCAB}$ operon that lead to constitutive activation of PmrAB, a two-component regulatory system responsible for sensing and responding to environmental conditions via regulation of gene expression involved in lipid A synthesis, result in induction of the PmrC transferase [31-33]. PmrC overexpression leads to the addition of phosphoethanolamine to lipid A phosphates, which in turn reduces the negative charge of the lipopolysaccharide (LPS), ultimately compromising the essential interaction between the polymyxins and LPS. Third, the addition of galactosamine to lipid A phosphates also diminishes the polymyxin-LPS interaction by reducing the negative charge of the LPS [34]. To date, the plasmid-mediated colistin resistance gene, $\mathrm{mcr}$, has not been reported in clinical isolates of $\mathrm{AB}$, although a recent report identified an $\mathrm{AB}$ strain isolated from pig feces in China harboring $m c r-4.3$ [35]. Due to its transmissibility, it is possible that $m c r$-harboring $\mathrm{AB}$ strains will be clinically encountered in the near future, 







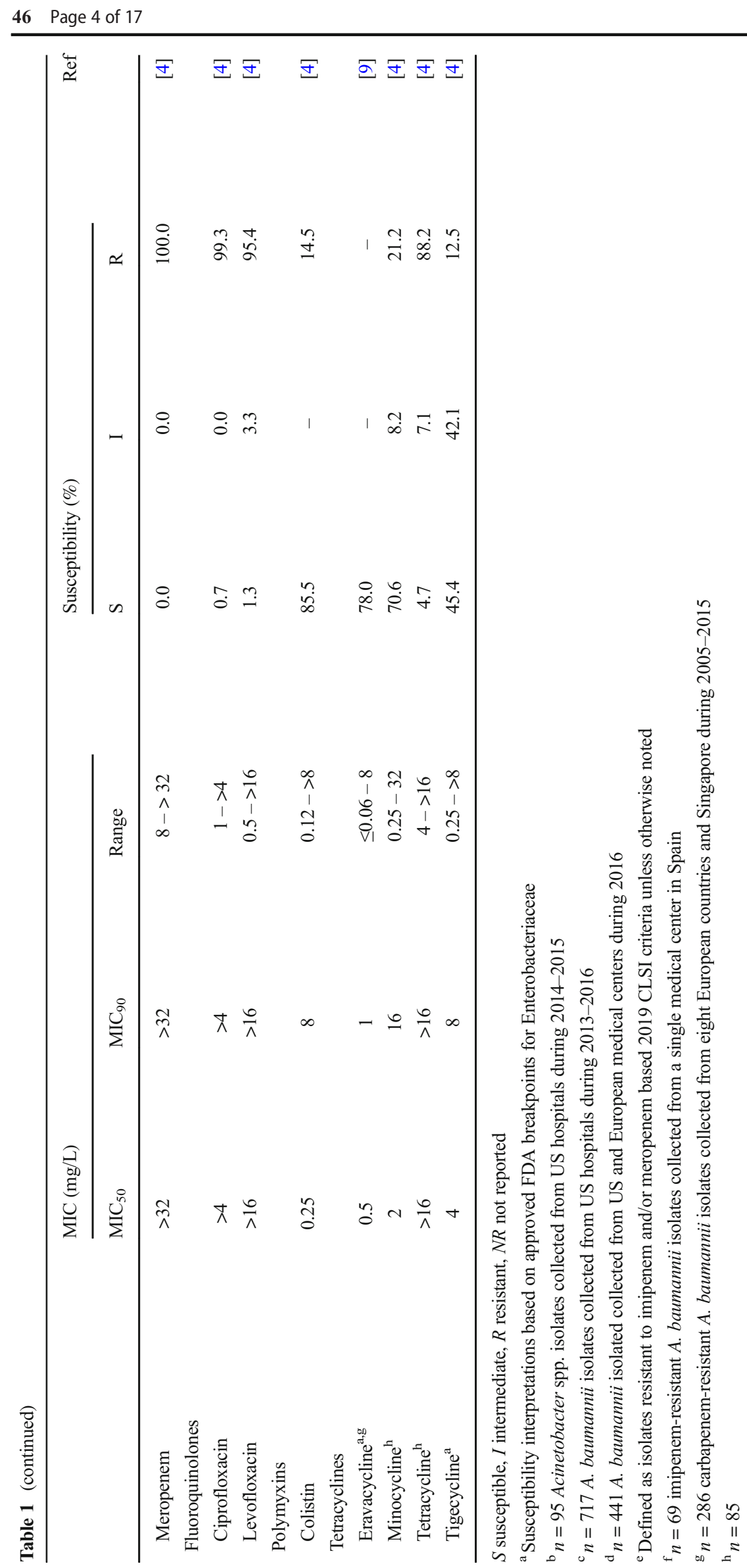

Curr Infect Dis Rep (2019) 21: 46

望 Springer 
although the fitness cost associated with $m c r-1$ expression may limit its pathogenicity [36].

\section{Tetracyclines}

Similar to the polymyxins, there has been a renewed interest in the clinical use and development of tetracyclines due to their potent activity against $A B$, especially MDR strains like CRAB. Importantly, activity varies between individual agents within the tetracycline class. Generally speaking, the potency against $\mathrm{AB}$ is as follows: tetracycline $<$ doxycycline $<$ omadacycline $<$ tigecycline $<$ minocycline $<$ eravacycline $[37,38]$. Resistance to tetracyclines may be attributed to four general mechanisms: efflux, ribosomal protection, target modification, and enzymatic inactivation [39]. In AB, tetracycline efflux may be mediated by the presence of acquired and/or intrinsically produced tetracycline-specific pumps. Tet(A) and Tet(B) are the most common tetracycline-specific efflux pumps encountered in $\mathrm{AB}$ and both pumps confer resistance to tetracycline and doxycycline whereas only Tet(B) influences minocycline resistance [40]. The newer generation tetracycline analogues (i.e., tigecycline, eravacycline, and omadacycline) are largely unaffected by the presence of Tet(A) or Tet(B) [9, 41]. Further, all tetracyclines are substrates for the AdeABC efflux pump, although the pump is more specific for tetracycline, tigecycline, and eravacycline than doxycycline or minocycline [42-44]. Additionally, minocycline and tigecycline are each substrates for both the AdeFGH and AdeIJK efflux pumps [42].

Ribosomal protection proteins, or RPPs, facilitate the dissociation of tetracyclines from their ribosomal binding site. The two most well-described RPPs are $\operatorname{Tet}(\mathrm{M})$ and $\operatorname{Tet}(\mathrm{O})$, which confer resistance to tetracycline, doxycycline, and minocycline, but spare tigecycline, eravacycline, and omadacycline due to the presence of side chains at the C9 position of the D-ring [45]. The activity of tigecycline, and its predecessors, may be diminished in $\mathrm{AB}$ due to modifications at the ribosomal binding site such as those caused by mutations in rps $J$ or trm [46, 47]. The effect of these mutations on the activities of eravacycline and omadacycline is largely unknown at this time, although previous data demonstrate elevated eravacycline MICs in Klebsiella pneumoniae isolates harboring rps $J$ mutations [48]. Finally, all currently available tetracyclines are prone to enzymatic inactivation by the presence of Tet(X), which causes covalent inactivation by adding a hydroxyl group at position C-11a [49].

\section{Aminoglycosides}

Aminoglycosides remain one of the most active antimicrobial classes in vitro against $\mathrm{AB}$, with approximately $80 \%$ of isolates retaining susceptibility against at least one agent (Table 1). Among aminoglycoside-resistant isolates, the major determinant of aminoglycoside resistance is the presence of aminoglycoside-modifying enzymes (AMEs), which can be further classified into acetyltransferases, adenyltransferases, and phosphotransferases [50]. These AMEs are often coharbored on plasmids carrying carbapenemases, making aminoglycoside resistance more common among CRAB. Additionally, the aminoglycosides are impacted to a different degree by CRAB isolates harboring AMEs. In a study of CRAB isolates collected from 8 US metropolitan areas from 2012-2015, susceptibility rates to amikacin, gentamicin, and tobramycin were $61.1 \%, 30.7 \%$, and $59.9 \%$, respectively [51]. The neoglycoside agent plazomicin retains activity against pathogens harboring AMEs, but has limited activity against $\mathrm{AB}(\sim 65 \%$ susceptible) [52] given the frequent presence of other mechanisms of aminoglycoside resistance including efflux pumps (AdeABC and AdeDE) [7, 53] and ribosomal methylation (rMTs) [10].

\section{Fluoroquinolones}

Widespread resistance has considerably compromised the place in therapy of fluoroquinolones for treatment of $\mathrm{AB}$ infections (Table 1). Phenotypic changes in the fluoroquinolone targets topoisomerase II (DNA gyrase) and topoisomerase IV, due to mutations in the $\operatorname{gyr} A, \operatorname{gyr} B$, and $\operatorname{par} C$ genes, are the primary mechanism of fluoroquinolone resistance among $\mathrm{AB}$ isolates [11, 54]. The binding affinity of fluoroquinolones to DNA gyrase and topoisomerase IV may also be compromised by the presence of plasmid-encoded determinants $q n r A, q n r B$, and qnrS [55-57]. Efflux-mediated resistance by AdeABC and AdeFGH may also play a role in fluoroquinoloneresistance [58].

\section{Rapid Diagnostics}

Accurate and rapid diagnosis of $\mathrm{AB}$ infections is critical to the timely selection of effective antibiotic therapy. Acinetobacter spp. are strictly aerobic, non-fermenting, Gram-negative coccobacilli [59]. Historically, the identification of Acinetobacter spp. has been difficult via conventional microbiology techniques given their unique morphology, the fact that they are often Gram-variable on Gram stain, there is no single metabolic test to distinguish the genus from other nonfermenting Gram-negative bacteria, and phenotypic/DNADNA hybridization assays do not distinguish between the species within the ABC species complex [59-61]. Fortunately, the past decade has brought cutting-edge technologies in the form of RDTs to the clinical microbiology lab that provide more accurate and rapid results compared to conventional microbiology methods $[62,63]$. These RDTs have significantly improved the ability to identify $\mathrm{AB}$ down to the species level, which is crucial given the propensity for the 
ABC complex to cause disease in humans and possess an MDR phenotype [1, 13, 51, 64-66].

There are currently several genotypic and phenotypic RDTs that support the species identification, resistance determinant detection, and/or susceptibilities of $\mathrm{AB}$ isolates (Table 2). Of these platforms, the ePlex BCID-GN panel and the Verigene $\mathrm{BC}-\mathrm{GN}$ assay are the most comprehensive for bloodstream infections due to $\mathrm{AB}$. The primary difference between these platforms is that the ePlex BCID-GN is able to identify AB to the species level, while the Verigene BC-GN assay is limited to genus identification [22, 67-69]. The detection of genotypic markers of resistance in $\mathrm{AB}$ (i.e., bla $a_{O X A}$ ) has been shown to correlate well with subsequent phenotypic susceptibilities. In a multicenter study by Pogue et al., the absence of $b l a_{O X A}$ detection in AB by Verigene BC-GN was highly predictive of phenotypic meropenem susceptibility (93\% negative predictive value), and vice versa [23]. Although limited by isolate count and the absence of detecting other mechanisms of resistance, this genotypic and phenotypic correlation allows for rapid escalation or de-escalation of antimicrobial therapy and dramatically improves time to effective therapy, which allows for the implementation of genotypic-phenotypic antibiograms and care pathways.

It is essential that RDTs are employed in conjunction with active antimicrobial stewardship (AMS) intervention in order to improve patients' clinical outcomes, particularly mortality. The combination of RDT + AMS intervention decreases mortality primarily by improving the time to effective antimicrobial therapy. Patients with infections due to MDR AB often experience long delays in time to effective therapy given the baseline resistance present in the majority of isolates negating the typical first-line antimicrobial agents. This has been demonstrated in a study by Wenzler et al. in which identification of
AB by MALDI-TOF MS in patients with pneumonia and/or bacteremia along with AMS intervention resulted in decreased time to effective therapy compared to conventional identification methods and was associated with an increase in clinical cure [70]. Future RDT advances that will impact treatment of $\mathrm{AB}$ infections include utilizing non-blood RDTs to diagnose AB pneumonia. Accordingly, Entasis Therapeutics has incorporated the BioFire® FilmArray Pneumonia Panel to provide earlier organism identification in order to optimize enrollment into their phase 3 study of ETX2514SUL for the treatment of serious infections due to ABC complex (NCT03894046) [71].

\section{Treatment}

There have been several recent advances toward improving the safety and efficacy of current therapeutic options for AB including additional pre-clinical and clinical data regarding optimal treatment of AB infections, new guidelines (Table 3), and the availability of new antibiotics.

\section{$\boldsymbol{\beta}$-Lactams}

$\beta$-Lactams are the drugs of choice against susceptible AB infections [1, 81]. However, just $26 \%$ of MDR AB in the USA remains susceptible to one or more first line agents, including carbapenems or sulbactam [2, 3•, 82•]. Despite low rates of in vitro susceptibility, the $\beta$-lactams, typically carbapenems, may be effectively utilized as part of a treatment regimen for $\mathrm{MDR} \mathrm{AB}$ via optimization of $\mathrm{PK} / \mathrm{PD}$ parameters (high dose, extended infusion) and combining with another agent that improves its bactericidal activity (polymyxins). In vitro, carbapenem-polymyxin combinations frequently

Table 2 Commercially available rapid diagnostic tests relevant to Acinetobacter spp.

\begin{tabular}{|c|c|c|c|c|c|}
\hline Test & Technology & Identification & Resistance markers detected & Source & $\begin{array}{l}\text { FDA } \\
\text { approved }\end{array}$ \\
\hline Verigene BC-GN & Nucleic acid test & Acinetobacter spp. & $\begin{array}{l}\text { bla }_{\mathrm{CTX}-\mathrm{M}}, \text { bla }_{\mathrm{KPC}}, \text { bla } \\
\text { bla }_{\mathrm{NMP}}, \text { bla } \\
\text { bla }_{\mathrm{OXA}-48}, \text { bla }_{\mathrm{OIM}}-40, \text { bla }_{\mathrm{OXA}-23} \\
\text { OXA-58 }\end{array}$ & $\begin{array}{l}\text { Positive } \\
\text { blood } \\
\text { culture }\end{array}$ & Yes \\
\hline Accelerate Pheno & $\begin{array}{l}\text { Morphokinetic } \\
\text { cellular analysis }\end{array}$ & A. baumannii & $\begin{array}{l}\text { Susceptibilities to } \\
\text { piperacillin-tazobactam } \\
\text { and amikacin }\end{array}$ & $\begin{array}{l}\text { Positive } \\
\text { blood } \\
\text { culture }\end{array}$ & Yes \\
\hline Unyvero & Multiplex PCR & Acinetobacter spp. & 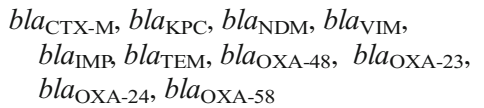 & $\begin{array}{l}\text { Endotracheal } \\
\text { aspirate }\end{array}$ & Yes \\
\hline $\begin{array}{l}\text { Biofire FilmArray } \\
\text { Blood } \\
\text { Culture ID } 2 \text { Panel }\end{array}$ & Multiplex PCR & $\begin{array}{l}\text { Acinetobacter } \\
\text { calcoaceticus-baumannii } \\
\text { complex }\end{array}$ & $\begin{array}{l}b^{b l a_{\mathrm{KPC}}}, \text { bla }_{\mathrm{NDM}}{ }^{*}, \text { bla }_{\mathrm{VIM}}{ }^{*}, b l a_{\mathrm{IMP}}{ }^{*} \\
\quad \text { bla }_{\mathrm{OXA}-48-1 \mathrm{like}} *\end{array}$ & $\begin{array}{l}\text { Positive } \\
\text { blood } \\
\text { culture }\end{array}$ & $\mathrm{No}^{\mathrm{a}}$ \\
\hline $\begin{array}{l}\text { Biofire FilmArray } \\
\text { Pneumonia Panel }\end{array}$ & & & None & BAL, sputum & Yes \\
\hline
\end{tabular}

$P C R$ polymerase chain reaction, $B A L$ bronchoalveolar lavage

*New resistance targets that will be added to the current FDA-approved FilmArray BCID Panel

${ }^{a}$ The Blood Culture ID 2 Panel is currently research use only, while the FilmArray BCID Panel is FDA-approved 


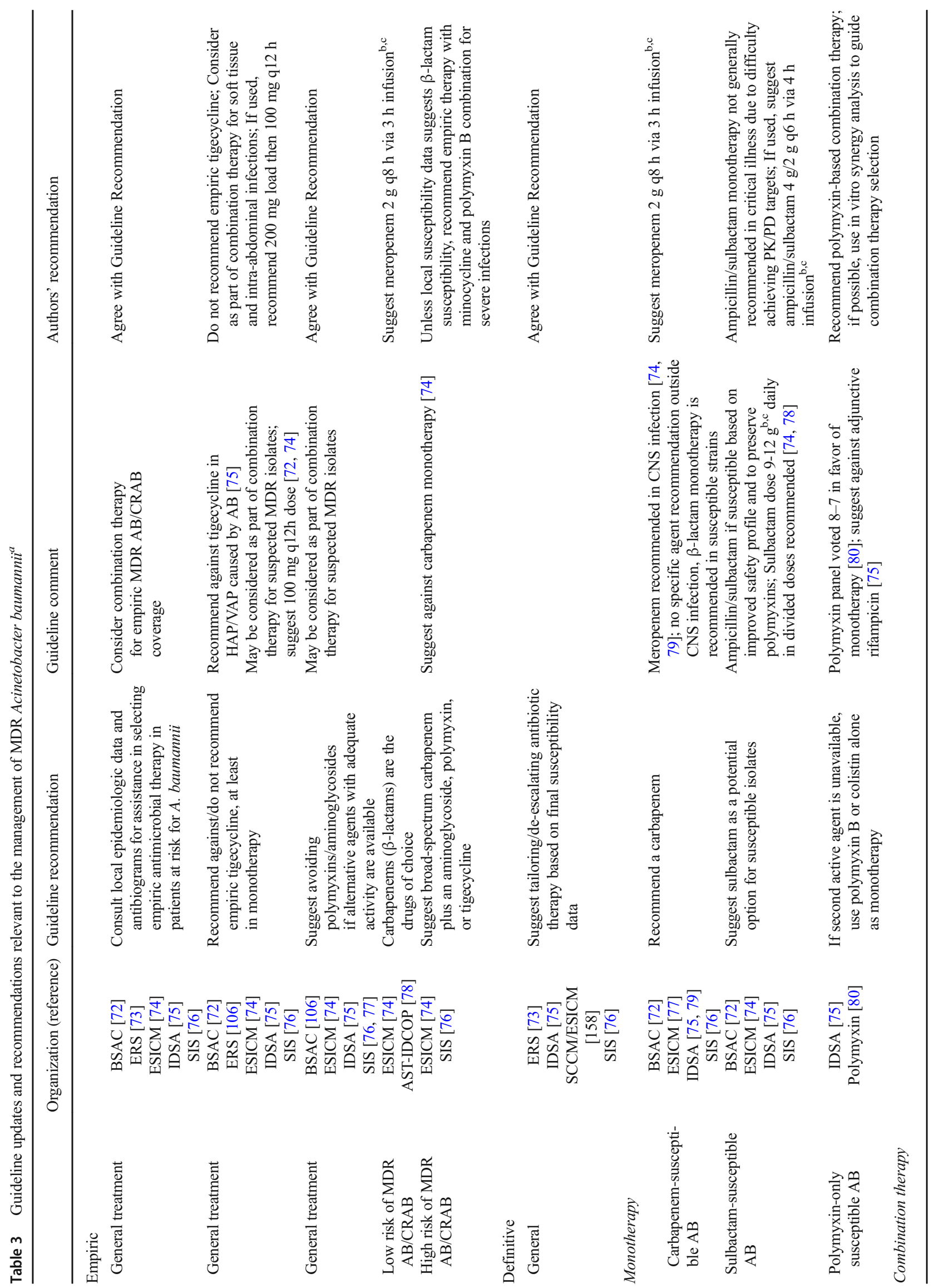




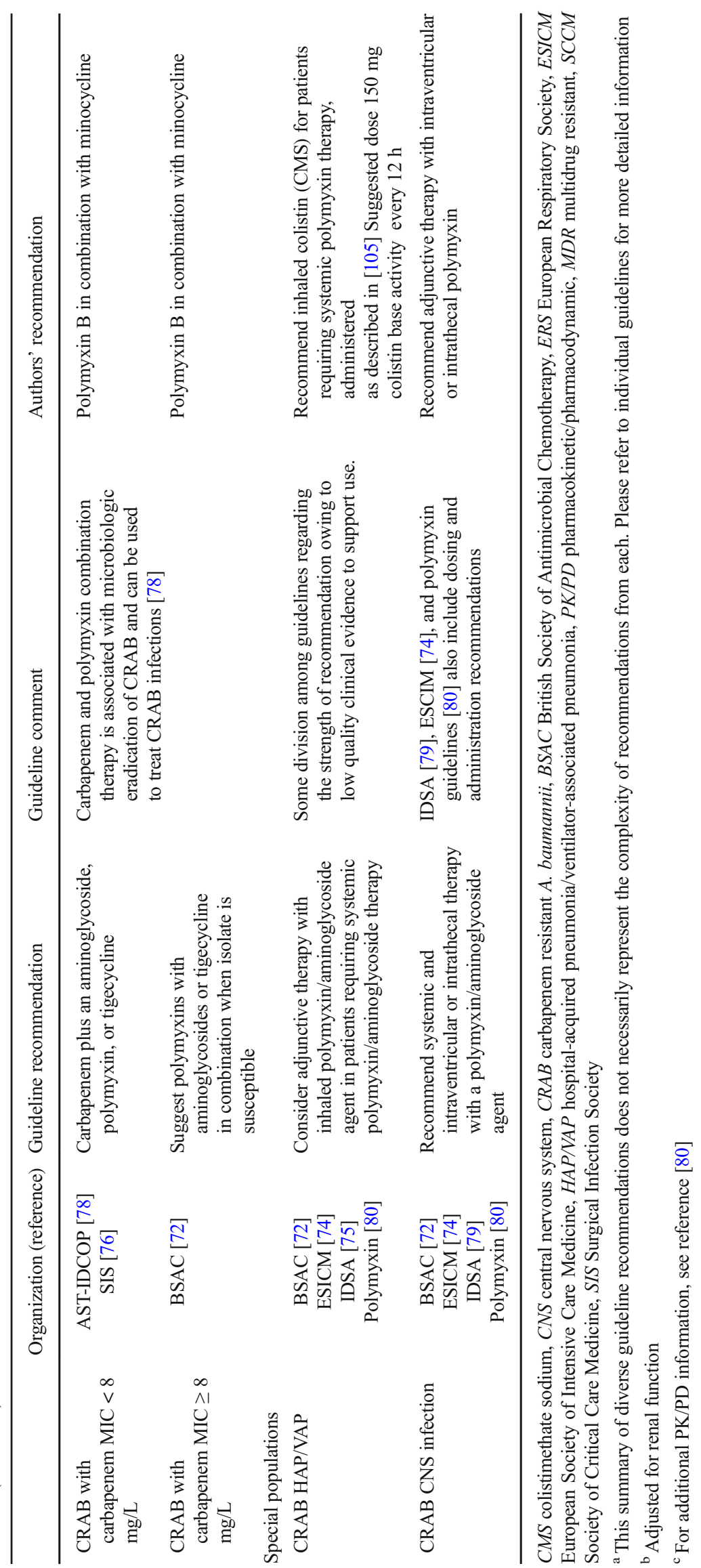


demonstrate synergy and improved bactericidal activity compared to either agent alone, especially against $\mathrm{AB}$ [83]. Previous data have suggested that the efficacy of this combination is maximized when the meropenem MIC is $\leq 8 \mathrm{mg} / \mathrm{L}$ and it is administered as a high dose, extended infusion regimen in combination with a polymyxin $[84,85]$. These findings were confirmed in the recent AIDA study, a prospective, multicenter, open-label randomized clinical trial [86]. AIDA sought to answer whether colistin plus high dose extended infusion meropenem ( $2 \mathrm{~g}$ every $8 \mathrm{~h}$ infused over $3 \mathrm{~h}$ ) improved clinical success and mortality compared to colistin monotherapy in patients with severe infections (hospital-acquired pneumonia (HAP), ventilator-associated pneumonia (VAP), bacteremia, or urosepsis) caused by carbapenem non-susceptible bacteria. The majority of subjects had pneumonia or bacteremia $(87 \%, 355 / 406)$ with $\mathrm{AB}$ being the most common pathogen $(77 \%, 312 / 406)$. Unfortunately, $97 \%$ of AB isolates had meropenem MICs $>8 \mathrm{mg} / \mathrm{L}$, likely obfuscating the true benefit, if any, of carbapenem-polymyxin combination therapy. There was a trend toward reduced clinical failure with combination therapy in the most severe infection types (73\% vs. $82 \% p=0.059)$, but nearly every clinical endpoint including 14- and 28-day mortality showed a lack of benefit for adding meropenem to colistin for CRAB infections. Moreover, among patients with isolates later confirmed to be colistinresistant by the central laboratory, combination therapy with meropenem and colistin was associated with increased mortality compared to colistin monotherapy $[87 \bullet \bullet]$.

In addition to traditional $\beta$-lactams, the $\beta$-lactamase inhibitor sulbactam has in vitro activity against Acinetobacter species and recent studies have continued to explore its utility in patients. Two meta-analyses assessed the use of sulbactam in patients with severe infections due to MDR $A B$ and XDR AB and concluded that sulbactam-based regimens had comparable effectiveness to alternative antimicrobial regimens [88, 89]. Another meta-analysis found that sulbactam-based therapies were comparable to carbapenem and polymyxin therapies but that clinical response was higher with doses of sulbactam $\geq 9$ grams/day [90]. Population PK and Monte Carlo simulations have demonstrated that in patients with severe sepsis due to $\mathrm{AB}$, high dose extended infusion sulbactam $(2 \mathrm{~g}$ every $6 \mathrm{~h}$ infused over $4 \mathrm{~h}$ ) may achieve $90 \%$ probability of target attainment (PTA) at $60 \%$ time above the MIC $\left(60 \% f \mathrm{~T}_{>\mathrm{MIC}}\right)$ for $\mathrm{AB}$ isolates with sulbactam MICs $\leq 16 \mathrm{mg} / \mathrm{L}$ [91, 92]. However, sulbactam doses $>12 \mathrm{~g} /$ day would be necessary to achieve 90\% PTA against most MDR AB isolates encountered outside North America $\left(\mathrm{MIC}_{50}>16 \mathrm{mg} / \mathrm{L}\right)$ [74, 82, 91]. These high dose sulbactam regimens ( $12 \mathrm{~g} /$ day) have also demonstrated promise as part of dual or triple combination regimens in in vitro hollow fiber infection models and may warrant additional investigation [75, 79].

For the treatment of $\beta$-lactam susceptible $A B$, guidelines generally recommend a carbapenem administered as a prolonged infusion [76-78, 93]. The American Society of Transplantation Infectious Diseases Community of Practice (AST IDCOP), which is among the few guidelines that have been updated since the publication of the AIDA trial, continues to recommend carbapenem and polymyxin combination therapy for CRAB infections in transplant patients on the basis of improved microbiologic eradication [93]. For sulbactam, conditional recommendations are given for use as pathogendirected therapy among susceptible isolates, including CRAB [77, 93-95]. When used, 9-12 $\mathrm{g}$ of daily sulbactam in divided doses infused over $4 \mathrm{~h}$ has been recommended for severe infections [78, 93]. Finally, guidelines for the optimization of treatment with $\beta$-lactams by the French Society of Pharmacology and Therapeutics (SFPT) recommend prolonged or continuous infusions $\beta$-lactams for isolates with high MICs (e.g., near the susceptibility breakpoint) and in patients who are critically ill [96].

Although several new $\beta$-lactam $/ \beta$-lactamase inhibitor agents have been approved for the treatment of MDR Gram-negative pathogens like carbapenem-resistant Enterobacteriaceae, none of them (ceftazidimeavibactam, ceftolozane-tazobactam, meropenemvaborbactam, imipenem-relebactam) have any appreciable activity against CRAB. Fortunately, novel $\beta$-lactambased agents are currently in the developmental pipeline with activity against MDR AB including cefiderocol and ETX2514. Cefiderocol is a siderophore cephalosporin with activity against CRAB including isolates producing serine carbapenemases and metallo- $\beta$-lactamases. Currently proposed dosing provides $>90 \%$ PTA with a PK/PD target of $75-85 \% f \mathrm{~T}_{>\mathrm{MIC}}$ for MICs $\leq 4 \mathrm{mg} / \mathrm{L}$ [92, 97, 98]. Cefiderocol demonstrated non-inferiority to imipenem in a Phase 2 clinical trial for complicated urinary tract infection (cUTI) involving Enterobacteriaceae and Pseudomonas aeruginosa and Phase 3 trials for HAP/VAP and carbapenem-resistant Gram-negative pathogens have recently completed but results are not yet available [98-101]. ETX2514 is a diazabicyclooctenone $\beta$-lactamase inhibitor currently in development in combination with sulbactam specifically for the treatment of AB. ETX2514 has potent activity against Ambler class $\mathrm{A}, \mathrm{C}$, and $\mathrm{D} \beta$-lactamases, and also enhances the bactericidal activity of sulbactam against $\mathrm{AB}$ by binding PBP2 [102]. Having recently completed a Phase 2 clinical trial for cUTI, a Phase 3 trial is currently recruiting to evaluate the efficacy and safety of sulbactam-ETX2514 in the treatment of patients with infections due to $\mathrm{ABC}$ complex (NCT03894046) [72, 73, 80, 103]. Ultimately, although these new $\beta$-lactam-based agents may have promising activity against $\mathrm{AB}$, carbapenems remain an important treatment option for infections caused by $\mathrm{AB}$ with low MICs (e.g., meropenem MICs $\leq 8 \mathrm{mg} / \mathrm{L}$ ). While some data support the use of sulbactam for $\mathrm{AB}$ infections, large scale clinical trials are absent and PK/PD analyses do not favor its routine use as 
monotherapy for a majority of the AB isolates outside North America [74, 82•, 91].

\section{Polymyxins}

Over the last two decades, polymyxins became the backbone of therapy for MDR AB, and specifically CRAB infections. Among available studies, the reported mortality rates of severe MDR AB infections treated with polymyxins cluster between 30 and $60 \%$, in part reflecting frequent limitations of many polymyxin clinical trials, such as a lack of standardized polymyxin susceptibility testing and dosing [81]. The recent AIDA trial used standardized intravenous colistin dosing, including a loading dose, for severe infections due to colistinsusceptible, carbapenem-resistant Gram-negative bacteria, yet the 28-day mortality rate was still 49\% (154/312) among patients with severe CRAB infections [86]. Secondary analyses of CRAB infections showed that active empiric therapy with colistin was not associated with improved survival compared to inactive therapy ( $p=0.504)$, nor was subsequent colistinresistance confirmed by broth microdilution (19\% (52/266) of available CRAB isolates) associated with lower survival [87••, 104]. In fact, both secondary analyses showed a trend toward reduced mortality when either inactive empirical treatment was prescribed or the CRAB isolate was colistin resistant. In part due to limitations of the trial itself, a trend toward reduced mortality in colistin-resistant isolates also hints at the tradeoff between colistin-resistance and virulence as previously noted.

International polymyxin guidelines have been published and may help to standardize the clinical use and investigational use of these last-line agents [105]. Most significantly, the polymyxin guidelines include dosing recommendations for colistin and polymyxin B in multiple clinical scenarios including renal replacement therapy. Overall, guideline bodies generally recommend avoiding polymyxins when possible, but consider combination therapy with aggressively dosed polymyxins to be the workhorse for CRAB infections [76-78, 92, $93,106,107]$. Additionally, administering the polymyxins by alternative routes such as via inhalation may help to maximize their efficacy and minimize toxicity, although clinical data supporting their use in nosocomial pneumonia due to $\mathrm{AB}$ are conflicting [108, 109].

In addition to alternative routes of administration, several novel polymyxin derivatives are in development designed to improve efficacy and reduce toxicity. A review of these novel polymyxin agents is available elsewhere [110]. One such agent is SPR741, a low toxicity polymyxin analog with limited intrinsic activity which can potentiate the activity of many antimicrobials by permeabilizing the outer membrane of Gram-negative bacteria thereby increasing the penetration of antimicrobials to their intracellular targets [111]. The antibiotic to be paired with SPR741 has not been announced, but significant potentiation of activity against MDR AB has been noted for rifampin, macrolides, and $\beta$-lactams [111]. SPR741 was generally well tolerated in a recent Phase I clinical trial with 4 of 6 patients in the highest dosing cohort of SPR741 (600 mg every $8 \mathrm{~h}$ for 14 days) experiencing a reversible mild or moderate decrease in creatinine clearance [112]. As a whole, the polymyxins remain a backbone in treatment of $\mathrm{AB}$ infections and continued efforts into dose optimization and understanding their use in combination will be critical to their continued effectiveness.

\section{Tetracyclines}

Tetracyclines are second only to polymyxins for most reliable in vitro activity against $\mathrm{AB}$ and are often the drugs of choice for combination therapy against CRAB. Most recent studies were retrospective in design and nearly all featured tigecycline in combination with a variety of other agents including polymyxins, $\beta$-lactams, and aminoglycosides [113-115]. The use of tigecycline for bacteremia is still cautioned, however, as a prospective multicenter study of empiric tigecycline-based salvage therapies for persistent febrile neutropenia $(>72 \mathrm{~h}$ ) demonstrated the risk of treatment failure in bacteremia was over 4-fold higher than non-bacteremic infections (OR 4.42; 95\% CI 1.41-13.89, $p=0.011$ ) [116]. Overall, systemic tigecycline-based therapies compared unfavorably to alternatives for MDR AB when assessed by both traditional and Bayesian network meta-analyses [88, 89, 117]. Though results have not been confirmed by large clinical trials, unfavorable outcomes with tigecycline may be potentially offset by using higher dosages (e.g., $200 \mathrm{mg}$ loading dose, $100 \mathrm{mg}$ every 12 h) $[118,119]$.

Eravacycline, a tetracycline analogue, is 2- to 4-fold more potent than tigecycline against CRAB [120]. The eravacycline registrational clinical trials in the treatment of complicated intra-abdominal infection (cIAI) included 13 patients with infections due to AB, all of whom achieved clinical and microbiologic cure on pooled microbiologic analysis [121]. New clinical trial data for minocycline is unavailable, but many practitioners continue to view it as a favorable alternative due to high in vitro activity and previous clinical successes against MDR AB, especially in higher doses (e.g., $400 \mathrm{mg}$ loading dose, $200 \mathrm{mg}$ every $12 \mathrm{~h}$ ) [122-124].

Updated guidelines reflect the somewhat divisive clinical data regarding tetracycline agents for $\mathrm{AB}$ infection. There is consensus recommendation against the empiric use of tigecycline in HAP/VAP, with suggested use in combination with other agents for the treatment of MDR AB soft tissue and intra-abdominal infections [77, 78, 93, 94, 106]. When tigecycline is used, the British Society of Antimicrobial Chemotherapy recommends tigecycline dosages of $100 \mathrm{mg}$ twice daily [106]. Though minocycline is largely absent from treatment guidelines, the ASTIDCOP do issue a weak 
recommendation in favor of its use as an alternative treatment option for CRAB [93].

New tetracycline-derivatives for the treatment of MDR AB are also in development. One notable agent is TP-6076, a fully synthetic tetracycline with potent in vitro activity against CRAB $\left(\mathrm{MIC}_{50 / 90} 0.03 / 0.06 \mathrm{mg} / \mathrm{L}\right)$ [125]. Available data shows potent in vivo efficacy of TP-6076 in murine infection models, but it may also have non-linear PK and dose limiting nausea similar to others of the class [126, 127]. Development of this agent was recently halted by the sponsor in order to focus on eravacycline, so it is unclear if or when TP-6076 will be clinically available [128]. Overall, although clinical data are largely lacking, tetracycline compounds such as tigecycline, minocycline, and eravacycline are likely to be the second most active agents in vitro against $\mathrm{AB}$ behind the polymyxins. As discussed, tigecycline should generally be avoided in favor of minocycline or eravacycline if possible, and nuanced differences in vulnerability to AB's tetracycline resistance mechanisms are important to recognize. Finally, the future of the tetracyclines in the treatment of serious $\mathrm{AB}$ infections will likely depend in large part on generating more robust PK/PD data for which to establishing optimal dosing regimens and accurate exposure-response relationships.

\section{Other Agents}

The aminoglycosides, fluoroquinolones, and fosfomycin are typically used in combination with other agents for the treatment of CRAB. Although new agents from these classes have been approved, plazomicin (aminoglycoside) and delafloxacin (fluoroquinolone) do not offer significant improvements against $\mathrm{AB}$ compared to other drugs from their respective classes $[129,130]$. There have been no reports to date demonstrating efficacious use of plazomicin or delafloxacin in $\mathrm{AB}$ infections $[130,131]$. Intravenous fosfomycin is expected to be available in the USA in the near future, but clinical data to support its use against $A B$ is still lacking [81]. As $\mathrm{AB}$ possesses intrinsic resistance against fosfomycin, fosfomycin has been recommended in very high doses as an extended infusion (e.g., $8 \mathrm{~g}$ every $8 \mathrm{~h}$ infused over $3 \mathrm{~h}$ ) and in combination with other agents on the basis of in vitro synergy and Monte Carlo Analysis [132].

Guidelines mirror the clinical data for aminoglycosides, fluoroquinolones, and fosfomycin, with a paucity of direct recommendations for MDR AB infections. When discussed, current guidelines advocate that aminoglycosides, fluoroquinolones, and/or fosfomycin may be an acceptable alternative therapy in susceptible isolates when used in combination with other agents $[77,93,94,105,106]$.

Apart from the previously mentioned intravenous fosfomycin, the only agent from these classes undergoing clinical development is apramycin, a veterinary aminoglycoside that is not subject to resistance due to RNA methylation
[133]. With increased in vitro activity against $\mathrm{AB}$ and purportedly reduced toxicity compared to traditional aminoglycosides, apramycin will make a welcome addition to potential combination therapies.

\section{Non-Antibiotic Therapies}

Some of the most forward-thinking strategies in the treatment of MDR AB are non-small molecule therapies. One such example is the use of bacteriophages which are viruses that parasitize bacteria, and have bacterial host-specificity which is often species or even strain-specific [134, 135]. Though in their infancy, bacteriophages have been effectively used in the prevention of MDR AB infection through environmental aerosolization [136], and the treatment of MDR AB infection through systemic and local administration [137-140].

Also under investigation are monoclonal antibodies for the treatment of MDR AB infections which target capsular polysaccharides with the intent to opsonize bacteria and improve clearance by macrophages [141]. Nielsen et al. evaluated a monoclonal antibody able to abolish mortality in lethal murine models of MDR AB bacteremia, and having synergistic effect with colistin [142]. Conversely, a recent investigation into another anticapsular monoclonal antibody resulted in substantially increased bacterial burden and mortality in an $\mathrm{AB}$ pneumonia model [143]. This discordance highlights the complexity of $\mathrm{AB}$ infections and the disparity of effect that may be elicited by an immune response toward enhancing or hindering the clearance of infection.

\section{Approach to Antimicrobial Selection}

\section{Empiric Therapy}

As with all infections, patient risk factors and local antibiogram data should be utilized to inform and select optimal therapeutic options. If the isolate is strongly suspected to be susceptible to a $\beta$-lactam, or if RDTs do not detect a carbapenemase (e.g., OXA-negative by Verigene BC-GN), monotherapy with a carbapenem in sufficiently high doses to achieve effective concentrations at the site of infection is recommended. Preference is generally given to meropenem over other group 2 carbapenems as meropenem is less susceptible to OXA $\beta$-lactamases [144] and more clinical and translational evidence is available. Although many MDR AB isolates retain susceptibility to sulbactam, empiric therapy with carbapenems is preferred over sulbactam for several reasons: $\{1\}$ carbapenems have broader spectrum of activity for empiric coverage of critically ill patients, $\{2\} \mathrm{PK} / \mathrm{PD}$ targets of carbapenems are more easily achieved than sulbactam (> $40 \% f \mathrm{~T}_{>}$MIC vs. $>40-60 \% f \mathrm{~T}_{>}$MIC , respectively), and $\{3\}$ the increased incidence of acquired $\beta$-lactamases that 
hydrolyze sulbactam in MDR AB (e.g., TEM, ADC, OXA) presents a concern for its efficacy in monotherapy $[22,25,26$, $29,81]$.

When $\beta$-lactam resistance is suspected or MICs preclude the use of carbapenems, polymyxin-based combination therapies are recommended. Polymyxin B is the preferred agent over colistin due to its more predictable PK profile and decreased risk of nephrotoxicity [105]. Polymyxins should be used in combination with other agents for serious AB infections in order to achieve synergy and prevent the development of resistance. For empiric coverage of presumed CRAB in severe infections, the combination of polymyxin B (2.0-2.5 $\mathrm{mg} / \mathrm{kg}$ loading dose, $1.25-1.5 \mathrm{mg} / \mathrm{kg}$ every $12 \mathrm{~h}$; see polymyxin guidelines [105]) and minocycline (400 $\mathrm{mg}$ loading dose, $200 \mathrm{mg}$ every $12 \mathrm{~h}$ ) is suggested given their reliable in vitro susceptibility.

\section{Definitive Therapy}

For severe infections due to $\mathrm{AB}$ with meropenem $\mathrm{MIC} \leq 8$ $\mathrm{mg} / \mathrm{L}$, meropenem is recommended as monotherapy given as high dose extended infusion [76, 78, 93, 94, 106]. High dose extended infusion ampicillin-sulbactam with or without additional agents may also be an alternative for susceptible isolates $[77,78,93,106]$. In cases of CRAB where combination therapy was used empirically, therapy should be consolidated to two or fewer agents from different classes with known in vitro activity [77, 94, 107, 145]. Generally, this will be a combination of a polymyxin plus a secondary agent to which the CRAB is susceptible, if available. When polymyxins or aminoglycosides are used systemically in pneumonia or meningitis/ventriculitis, adjunctive inhaled or intrathecal/ intraventricular administration is recommended, respectively [76-78, 105, 106].

Polymyxin monotherapy may be an option in cases where it is the only susceptible agent or there are no other active agents available; however, a second agent (e.g., minocycline or ampicillin/sulbactam) should still be utilized if possible for the goal of achieving synergy [81]. Synergy is often strainspecific and selection of agents to use in combination with a polymyxin should consider patient-specific factors such as the source of the infection and potential toxicities of the combination $[94,105]$. If possible, isolates should be tested for in vitro synergy in the clinical microbiology laboratory to inform the clinical management of the patient. When tested in vitro against MDR $A B$, meropenem, sulbactam, and minocycline have all shown synergistic effect when combined with polymyxins [81]. Triple combination therapy has also shown significant promise in the ability to eradicate $A B$ that is resistant to all three agents, such as with the combination of polymyxin B, meropenem, and ampicillin/sulbactam [79].

Finally, in patients for whom oral therapy is considered to complete a treatment course, monotherapy with minocycline or ciprofloxacin/levofloxacin may be an acceptable option in susceptible isolates following clinical improvement after intravenous therapy.

\section{Conclusion}

The management of MDR AB infections has continued to be exceptionally challenging owing to a limited understanding of the pathogen's virulence, its near limitless ability to possess and acquire resistance, a paucity of adequate pre-clinical and clinical data, and a dearth of novel treatment options. At present, employing RDTs and aggressive antimicrobial combination therapy up front with de-escalation based on genotypic/ phenotypic susceptibilities is optimal for managing serious MDR AB infections. Importantly, several guidelines are now available that may help to standardize the treatment of $\mathrm{AB}$ and guide the use of agents with narrow therapeutic windows such as the polymyxins. Finally, continued advances in both the antimicrobial and non-antimicrobial treatment pipelines for $\mathrm{AB}$ will be essential for combating this difficult to treat pathogen.

\section{Compliance with Ethical Standards}

Conflict of Interest Eric Wenzler serves on the speaker's bureau for Melinta Therapeutics and Astellas Pharma and on the advisory board for Shionogi and Genmark Diagnostics. All other authors certify no potential conflicts of interest.

Human and Animal Rights and Informed Consent This article does not contain any studies with human or animal subjects performed by any of the authors.

\section{References}

Papers of particular interest, published recently, have been highlighted as:

- Of importance

•- Of major importance

1. Wong D, Nielsen TB, Bonomo RA, Pantapalangkoor P, Luna B, Spellberg B. Clinical and pathophysiological overview of Acinetobacter infections: a century of challenges. Clin Microbiol Rev. 2017;30(1):409-47.

2. Magiorakos AP, Srinivasan A, Carey RB, Carmeli Y, Falagas ME, Giske CG, et al. Multidrug-resistant, extensively drug-resistant and pandrug-resistant bacteria: an international expert proposal for interim standard definitions for acquired resistance. Clin Microbiol Infect. 2012;18(3):268-81.

3. Kadri SS, Adjemian J, Lai YL, Hooper DC, Spaulding AB, Ricotta E, et al. Difficult-to-treat resistance in Gram-negative bacteremia at 173 US Hospitals: retrospective cohort analysis of prevalence, predictors, and outcome of resistance to all first-line agents. Clin Infect Dis. 2018;67(12):1803-14 This large retrospective cohort study analyses the correlation of antibiotic 
resistance and clinical outcomes in Gram-negative bacteremia and proposes a new definition of antibiotic resistance defined by non-susceptibility of first-line agents.

4. Activity of antimicrobial agents when tested against 448 Acinetobacter baumannii-calcoaceticus species complex isolates in the SENTRY program collected from medical centers in North America from medical centers in USA during 2017 and 2018 [Internet]. JMI Laboratories, Inc. [cited 23 Jun 2019]. Available from: https://sentry-mvp.jmilabs.com/.

5. Shaw KJ, Rather PN, Hare RS, Miller GH. Molecular genetics of aminoglycoside resistance genes and familial relationships of the aminoglycoside-modifying enzymes. Microbiol Rev. 1993;57(1): 138-63.

6. Bouchillon S, Hawser S, Monti F, Morrissey I, Ditch K, Olesky $\mathrm{M}$, Fyfe C. Surveillance of the in vitro activity of eravacycline and comparators against clinical isolates from the USA from 20132016. Oral presentation at 38th Surgical Infection Society Annual Meeting; 22 Apr 2018. Westlake Village, CA, USA.

7. Pfaller MA, Huband MD, Shortridge D, Flamm RK. Surveillance of omadacycline activity tested against clinical isolates from the United States and Europe as part of the 2016 SENTRY antimicrobial surveillance program. Antimicrob Agents Chemother. 2018;62(4):e02327-17.

8. Garcia-Salguero C, Rodriguez-Avial I, Picazo JJ, Culebras E. Can Plazomicin Alone or in Combination Be a Therapeutic Option against Carbapenem-Resistant Acinetobacter baumannii? Antimicrob Agents Chemother 2015; 59(10):5959-66.

9. Seifert H, Stefanik D, Sutcliffe JA, Higgins PG. In-vitro activity of the novel fluorocycline eravacycline against carbapenem nonsusceptible Acinetobacter baumannii. Int J Antimicrob Agents. 2018;51(1):62-4.

10. Asif M, Alvi IA, Rehman SU. Insight into Acinetobacter baumannii: pathogenesis, global resistance, mechanisms of resistance, treatment options, and alternative modalities. Infect Drug Resist. 2018;11:1249-60.

11. Magnet S, Courvalin P, Lambert T. Resistance-nodulation-cell division-type efflux pump involved in aminoglycoside resistance in Acinetobacter baumannii strain BM4454. Antimicrob Agents Chemother. 2001;45(12):3375-80.

12. Grossman TH, Starosta AL, Fyfe C, O'Brien W, Rothstein DM, Mikolajka A, et al. Target- and resistance-based mechanistic studies with TP-434, a novel fluorocycline antibiotic. Antimicrob Agents Chemother. 2012;56(5):2559-64.

13. Shrestha S, Tada T, Shrestha B, Kirikae T, Ohara H, Rijal BP, et al. Emergence of aminoglycoside resistance due to armA methylase in multi-drug resistant Acinetobacter baumannii isolates in a University Hospital in Nepal. J Nepal Health Res Counc. 2016;14(33):72-6.

14. Vila J, Ruiz J, Goni P. Jimenez de Anta T. Quinolone-resistance mutations in the topoisomerase IV parC gene of Acinetobacter baumannii. J Antimicrob Chemother. 1997;39(6):757-62.

15. Hsu LY, Apisarnthanarak A, Khan E, Suwantarat N, Ghafur A, Tambyah PA. Carbapenem-resistant Acinetobacter baumannii and Enterobacteriaceae in South and Southeast Asia. Clin Microbiol Rev. 2017;30(1):1-22.

16. Cai B, Echols R, Magee G, Arjona Ferreira JC, Morgan G, Ariyasu M, et al. Prevalence of carbapenem-resistant Gram-negative infections in the United States predominated by Acinetobacter baumannii and Pseudomonas aeruginosa. Open Forum Infect Dis. 2017;4(3):ofx176.

17. Reinert RR, Low DE, Rossi F, Zhang X, Wattal C, Dowzicky MJ. Antimicrobial susceptibility among organisms from the Asia/Pacific Rim, Europe and Latin and North America collected as part of TEST and the in vitro activity of tigecycline. J Antimicrob Chemother. 2007;60(5):1018-29.
18. Al-Agamy MH, Jeannot K, El-Mahdy TS, Shibl AM, Kattan W, Plesiat P, et al. First detection of GES-5 carbapenemase-producing Acinetobacter baumannii isolate. Microb Drug Resist. 2017;23(5): 556-62.

19. Bogaerts P, Naas T, El Garch F, Cuzon G, Deplano A, Delaire T, et al. GES extended-spectrum beta-lactamases in Acinetobacter baumannii isolates in Belgium. Antimicrob Agents Chemother. 2010;54(11):4872-8.

20. Azimi L, Talebi M, Pourshafie MR, Owlia P, Rastegar LA. Characterization of carbapenemases in extensively drug resistance Acinetobacter baumannii in a Burn Care Center in Iran. Int J Mol Cell Med. 2015;4(1):46-53.

21. Robledo IE, Aquino EE, Sante MI, Santana JL, Otero DM, Leon $\mathrm{CF}$, et al. Detection of KPC in Acinetobacter spp. in Puerto Rico. Antimicrob Agents Chemother. 2010;54(3):1354-7.

22. Lee CR, Lee JH, Park M, Park KS, Bae IK, Kim YB, et al. Biology of Acinetobacter baumannii: pathogenesis, antibiotic resistance mechanisms, and prospective treatment options. Front Cell Infect Microbiol. 2017;7:55.

23. Palzkill T. Metallo-beta-lactamase structure and function. Ann N Y Acad Sci. 2013;1277:91-104.

24. Gordon NC, Wareham DW. Multidrug-resistant Acinetobacter baumannii: mechanisms of virulence and resistance. Int $\mathrm{J}$ Antimicrob Agents. 2010;35(3):219-26.

25. Mugnier PD, Poirel L, Naas T, Nordmann P. Worldwide dissemination of the blaOXA-23 carbapenemase gene of Acinetobacter baumannii. Emerg Infect Dis. 2010;16(1):35-40.

26. Pogue JM, Heil EL, Lephart P, Johnson JK, Mynatt RP, Salimnia $\mathrm{H}$, et al. An Antibiotic stewardship program blueprint for optimizing Verigene BC-GN within an Institution: a tale of two cities. Antimicrob Agents Chemother. 2018;62(5) This antibiotic stewardship-driven analysis of Verigene BC-GN blood culture results is the first to show an actionable correlation between the absence of the blaOXA carbapenem resistance marker and Acinetobacter spp. susceptibility to meropenem.

27. Shapiro AB. Kinetics of sulbactam hydrolysis by $\beta$-lactamases, and kinetics of $\beta$-lactamase inhibition by sulbactam. Antimicrob Agents Chemother. 2017;61(12):e01612-7.

28. Gales AC, Seifert H, Gur D, Sader HS, Castanheira M, Jones RN. Antimicrobial susceptibility of Acinetobacter calcoaceticusAcinetobacter baumannii complex and Stenotrophomonas maltophilia clinical isolates: results from the SENTRY antimicrobial surveillance program (1997-2016). Open Forum Infect Dis. 2019;6(Supplement_1):S34-46.

29. Yang Y, Xu Q, Li T, Fu Y, Shi Y, Lan P, et al. OXA-23 Is a prevalent mechanism contributing to sulbactam resistance in diverse Acinetobacter baumannii clinical strains. Antimicrob Agents Chemother. 2019;63(1).

30. Krizova L, Poirel L, Nordmann P, Nemec A. TEM-1 betalactamase as a source of resistance to sulbactam in clinical strains of Acinetobacter baumannii. J Antimicrob Chemother. 2013;68(12):2786-91.

31. Kuo SC, Lee YT, Yang Lauderdale TL, Huang WC, Chuang MF, Chen CP, et al. Contribution of Acinetobacter-derived cephalosporinase-30 to sulbactam resistance in Acinetobacter baumannii. Front Microbiol. 2015;6:231.

32. Yang Y, Fu Y, Lan P, Xu Q, Jiang Y, Chen Y, et al. Molecular epidemiology and mechanism of sulbactam resistance in Acinetobacter baumannii isolates with diverse genetic backgrounds in China. Antimicrob Agents Chemother. 2018;62(3): e01947-17.

33. Moffatt JH, Harper M, Harrison P, Hale JD, Vinogradov E, Seemann T, et al. Colistin resistance in Acinetobacter baumannii is mediated by complete loss of lipopolysaccharide production. Antimicrob Agents Chemother. 2010;54(12):4971-7. 
34. Arroyo LA, Herrera CM, Fernandez L, Hankins JV, Trent MS, Hancock RE. The pmrCAB operon mediates polymyxin resistance in Acinetobacter baumannii ATCC 17978 and clinical isolates through phosphoethanolamine modification of lipid A. Antimicrob Agents Chemother. 2011;55(8):3743-51.

35. Adams MD, Nickel GC, Bajaksouzian S, Lavender H, Murthy AR, Jacobs MR, et al. Resistance to colistin in Acinetobacter baumannii associated with mutations in the PmrAB twocomponent system. Antimicrob Agents Chemother. 2009;53(9): 3628-34.

36. Beceiro A, Llobet E, Aranda J, Bengoechea JA, Doumith M, Hornsey M, et al. Phosphoethanolamine modification of lipid A in colistin-resistant variants of Acinetobacter baumannii mediated by the pmrAB two-component regulatory system. Antimicrob Agents Chemother. 2011;55(7):3370-9.

37. Chin CY, Gregg KA, Napier BA, Ernst RK, Weiss DS. A PmrBregulated deacetylase required for lipid a modification and polymyxin resistance in Acinetobacter baumannii. Antimicrob Agents Chemother. 2015;59(12):7911-4.

38. Ma F, Shen C, Zheng X, Liu Y, Chen H, Zhong L, et al. Identification of a novel plasmid carrying mer-4.3 in an Acinetobacter baumannii strain in China. Antimicrob Agents Chemother. 2019;(6):63.

39. Nang SC, Morris FC, McDonald MJ, Han ML, Wang J, Strugnell RA, et al. Fitness cost of mcr-1-mediated polymyxin resistance in Klebsiella pneumoniae. J Antimicrob Chemother. 2018;73(6): 1604-10.

40. Sutcliffe JA, O'Brien W, Fyfe C, Grossman TH. Antibacterial activity of eravacycline (TP-434), a novel fluorocycline, against hospital and community pathogens. Antimicrob Agents Chemother. 2013;57(11):5548-58

41. Nguyen F, Starosta AL, Arenz S, Sohmen D, Donhofer A, Wilson DN. Tetracycline antibiotics and resistance mechanisms. Biol Chem. 2014;395(5):559-75.

42. Akers KS, Mende K, Yun HC, Hospenthal DR, Beckius ML, Yu $\mathrm{X}$, et al. Tetracycline susceptibility testing and resistance genes in isolates of Acinetobacter baumannii-Acinetobacter calcoaceticus complex from a U.S. military hospital. Antimicrob Agents Chemother. 2009;53(6):2693-5.

43. Mendes R, Castanheira M, Armstrong E, Steenbergen J, Flamm $\mathrm{R}$. Omadacycline in vitro activity against a molecularly characterized collection of clinical isolates with known tetracycline resistance mechanisms. Presented at IDWeek 2018 [Poster \#1377]. San Francisco, CA, USA

44. Grossman TH. Tetracycline antibiotics and resistance. Cold Spring Harbor Perspect Med. 2016;6(4):a025387.

45. Coyne S, Courvalin P, Perichon B. Efflux-mediated antibiotic resistance in Acinetobacter spp. Antimicrob Agents Chemother. 2011;55(3):947-53.

46. Lomovskaya O, Sun D, King P, Dudley M. Tigecycline (TIG) but not minocycline (MINO) selects for clinically relevant effluxmediated resistance (R) in Acinetobacter spp. (ACB). In: Abstr 54th Intersci Conf Antimicrob Agents Chemother, Abstract C11087.

47. Honeyman L, Ismail M, Nelson ML, Bhatia B, Bowser TE, Chen $\mathrm{J}$, et al. Structure-activity relationship of the aminomethylcyclines and the discovery of omadacycline. Antimicrob Agents Chemother. 2015;59(11):7044-53.

48. Beabout K, Hammerstrom TG, Perez AM, Magalhaes BF, Prater AG, Clements TP, et al. The ribosomal S10 protein is a general target for decreased tigecycline susceptibility. Antimicrob Agents Chemother. 2015;59(9):5561-6.

49. Chen Q, Li X, Zhou H, Jiang Y, Chen Y, Hua X, et al. Decreased susceptibility to tigecycline in Acinetobacter baumannii mediated by a mutation in trm encoding SAM-dependent methyltransferase. J Antimicrob Chemother. 2014;69(1):72-6.
50. Abdallah M, Olafisoye O, Cortes C, Urban C, Landman D, Quale J. Activity of eravacycline against Enterobacteriaceae and Acinetobacter baumannii, including multidrug-resistant isolates, from New York City. Antimicrob Agents Chemother. 2015;59(3):1802-5.

51. Yang W, Moore IF, Koteva KP, Bareich DC, Hughes DW, Wright GD. TetX is a flavin-dependent monooxygenase conferring resistance to tetracycline antibiotics. J Biol Chem. 2004;279(50): 52346-52.

52. Bulens SN, Yi SH, Walters MS, Jacob JT, Bower C, Reno J, et al. Carbapenem-nonsusceptible Acinetobacter baumannii, 8 US Metropolitan areas, 2012-2015. Emerg Infect Dis. 2018;24(4): 727-34.

53. Castanheira M, Davis AP, Mendes RE, Serio AW, Krause KM, Flamm RK. In vitro activity of plazomicin against Gram-negative and Gram-positive isolates collected from U.S. hospitals and comparative activities of aminoglycosides against carbapenemresistant Enterobacteriaceae and isolates carrying carbapenemase genes. Antimicrob Agents Chemother. 2018;(8):62.

54. Chau SL, Chu YW, Houang ET. Novel resistance-nodulation-cell division efflux system AdeDE in Acinetobacter genomic DNA group 3. Antimicrob Agents Chemother. 2004;48(10):4054-5.

55. Park S, Lee KM, Yoo YS, Yoo JS, Yoo JI, Kim HS, et al. Alterations of gyrA, gyrB, and parC and activity of efflux pump in fluoroquinolone-resistant Acinetobacter baumannii. Osong Public Health Res Perspect. 2011;2(3):164-70.

56. Yang H, Hu L, Liu Y, Ye Y, Li J. Detection of the plasmidmediated quinolone resistance determinants in clinical isolates of Acinetobacter baumannii in China. J Chemother. 2016;28(5):4435 .

57. Touati A, Brasme L, Benallaoua S, Gharout A, Madoux J, De Champs C. First report of qnrB-producing Enterobacter cloacae and qnrA-producing Acinetobacter baumannii recovered from Algerian hospitals. Diagn Microbiol Infect Dis. 2008;60(3):28790.

58. Mirnejad R, Heidary M, Bahramian A, Goudarzi M, Pournajaf A. Evaluation of polymyxin B susceptibility profile and detection of drug resistance genes among Acinetobacter baumannii clinical isolates in Tehran, Iran during 2015-2016. Mediterr J Hematol Infect Dis. 2018;10(1):e2018044.

59. Coyne S, Rosenfeld N, Lambert T, Courvalin P, Perichon B. Overexpression of resistance-nodulation-cell division pump AdeFGH confers multidrug resistance in Acinetobacter baumannii. Antimicrob Agents Chemother. 2010;54(10):4389 93.

60. Peleg AY, Seifert H, Paterson DL. Acinetobacter baumannii: emergence of a successful pathogen. Clin Microbiol Rev. 2008;21(3):538-82.

61. Tjernberg I, Ursing J. Clinical strains of Acinetobacter classified by DNA-DNA hybridization. APMIS. 1989;97(7):595-605.

62. Gerner-Smidt P, Tjernberg I, Ursing J. Reliability of phenotypic tests for identification of Acinetobacter species. J Clin Microbiol. 1991;29(2):277-82.

63. Bauer KA, Perez KK, Forrest GN, Goff DA. Review of rapid diagnostic tests used by antimicrobial stewardship programs. Clin Infect Dis. 2014;59(Suppl 3):S134-45.

64. Sullivan KV. Advances in diagnostic testing that impact infection prevention and antimicrobial stewardship programs. Curr Infect Dis Rep. 2019;21(6):20.

65. Kostyanev T, Vilken T, Lammens C, Timbermont L, Van't Veen A, Goossens H. Detection and prevalence of carbapenem-resistant Gram-negative bacteria among European laboratories in the COMBACTE network: a COMBACTE LAB-Net survey. Int J Antimicrob Agents. 2019;53(3):268-74.

66. Chusri S, Chongsuvivatwong V, Rivera JI, Silpapojakul K, Singkhamanan K, McNeil E, et al. Clinical outcomes of 
hospital-acquired infection with Acinetobacter nosocomialis and Acinetobacter pittii. Antimicrob Agents Chemother. 2014;58(7): 4172-9.

67. European Centre for Disease Prevention and Control. Carbapenem-resistant Acinetobacter baumannii in healthcare settings 2016 [Available from: https://ecdc.europa.eu/sites/portal/ files/media/en/publications/Publications/8-Dec-2016-RRAAcinetobacter\%20baumannii-Europe.pdf. Accessed 03 Jun 2019.

68. Connolly LE, Riddle V, Cebrik D, Armstrong ES, Miller LG. A multicenter, randomized, double-blind, phase 2 study of the efficacy and safety of plazomicin compared with levofloxacin in the treatment of complicated urinary tract infection and acute pyelonephritis. Antimicrob Agents Chemother. 2018;62(4).

69. Kang CI, Kim J, Park DW, Kim BN, Ha US, Lee SJ, et al. Clinical practice guidelines for the antibiotic treatment of communityacquired urinary tract infections. Infect Chemother. 2018;50(1): 67-100.

70. Poirel L, Nordmann P. Carbapenem resistance in Acinetobacter baumannii: mechanisms and epidemiology. Clin Microbiol Infect. 2006;12(9):826-36.

71. Wenzler E, Goff DA, Mangino JE, Reed EE, Wehr A, Bauer KA. Impact of rapid identification of Acinetobacter baumannii via matrix-assisted laser desorption ionization time-of-flight mass spectrometry combined with antimicrobial stewardship in patients with pneumonia and/or bacteremia. Diagn Microbiol Infect Dis. 2016;84(1):63-8.

72. GlobeNewswire. Entasis therapeutics receives positive feedback from FDA end-of-phase 2 meeting for ETX2514SUL; signs rapid diagnostic agreement with bioMérieux 2019 [Available from: https://www.globenewswire.com/news-release/2019/02/05/ 1710540/0/en/Entasis-Therapeutics-Receives-Positive-Feedbackfrom-FDA-End-of-Phase-2-Meeting-for-ETX2514SUL-SignsRapid-Diagnostic-Agreement-with-bioM\%C3\%A9rieux.html. Accessed 20 Jun 2019

73. Sagan O YR, Yanev K, Fomkin R, Stone E, O'Donnell J, Miller A, Isaacs R, Srinivasan S. A double-blind, randomized, placebocontrolled study to evaluate the safety and efficacy of intravenous sulbactam-ETX2514 in the treatment of hospitalized adults with complicated urinary tract infections, including acute pyelonephritis. Poster presented at 29th European Congress of Clinical Microbiology and Infections Diseases; 2019 Apr 13-19; Amsterdam, Netherlands.

74. Isaacs R. ETX2514SUL (sulbactam/ETX2514SUL for treatment of Acinetobacter baumannii infections. Oral presentation at 2018 IDWeek; 2018 Oct 4. San Francisco, CA, USA.

75. Yokoyama Y, Matsumoto K, Ikawa K, Watanabe E, Morikawa N, Takeda Y. Population pharmacokinetic-pharmacodynamic target attainment analysis of sulbactam in patients with impaired renal function: dosing considerations for Acinetobacter baumannii infections. J Infect Chemother. 2015;21(4):284-9.

76. Lenhard JR, Smith NM, Bulman ZP, Tao X, Thamlikitkul V, Shin BS, et al. High-dose ampicillin-sulbactam combinations combat polymyxin-resistant Acinetobacter baumannii in a hollow-fiber infection model. Antimicrob Agents Chemother. 2017;61(3).

77. Tunkel AR, Hasbun R, Bhimraj A, Byers K, Kaplan SL, Scheld WM, et al. 2017 Infectious diseases society of America's clinical practice guidelines for healthcare-associated ventriculitis and meningitis. Clin Infect Dis. 2017;64(6):e34-65.

78. Kalil AC, Metersky ML, Klompas M, Muscedere J, Sweeney DA, Palmer LB, et al. Management of adults with hospital-acquired and ventilator-associated pneumonia: 2016 Clinical Practice Guidelines by the Infectious Diseases Society of America and the American Thoracic Society. Clin Infect Dis. 2016;63(5):e61e111.

79. Garnacho-Montero J, Dimopoulos G, Poulakou G, Akova M, Cisneros JM, De Waele J, et al. Task force on management and prevention of Acinetobacter baumannii infections in the ICU. Intensive Care Med. 2015;41(12):2057-75.

80. Lenhard JR, Thamlikitkul V, Silveira FP, Garonzik SM, Tao X, Forrest A, et al. Polymyxin-resistant, carbapenem-resistant Acinetobacter baumannii is eradicated by a triple combination of agents that lack individual activity. J Antimicrob Chemother. 2017;72(5):1415-20.

81. Rodvold KA, Gotfried MH, Isaacs RD, O’Donnell JP, Stone E. Plasma and Intrapulmonary concentrations of ETX2514 and sulbactam following intravenous administration of ETX2514SUL to healthy adult subjects. Antimicrob Agents Chemother. 2018;62(11).

82. Lim SMS, Sime FB, Roberts J. Multidrug-resistant Acinetobacter baumannii infections: current evidence on treatment options and role of $\mathrm{PK} / \mathrm{PD}$ in dose optimization. Int J Antimicrob Agents. 2019; An excellent review of PK/PD for AB infections including in vitro, in vivo, and clinical trials. The supplementary tables provide an enpansive list of in vitro and in vivo synergy studies over the last decade.

83. Activity of antimicrobial agents when tested against 568 CLSI 2019 MDR Acinetobacter baumannii-calcoaceticus species complex isolates in the SENTRY program collected during 2018 [Internet]. JMI Laboratories, Inc. Available from: https://sentrymvp.jmilabs.com/. Accessed 03 Jun 2019.

84. Zusman O, Avni T, Leibovici L, Adler A, Friberg L, Stergiopoulou T, et al. Systematic review and meta-analysis of in vitro synergy of polymyxins and carbapenems. Antimicrob Agents Chemother. 2013;57(10):5104-11.

85. Daikos GL, Tsaousi S, Tzouvelekis LS, Anyfantis I, Psichogiou M, Argyropoulou A, et al. Carbapenemase-producing Klebsiella pneumoniae bloodstream infections: lowering mortality by antibiotic combination schemes and the role of carbapenems. Antimicrob Agents Chemother. 2014;58(4):2322-8.

86. Tumbarello M, Trecarichi EM, De Rosa FG, Giannella M, Giacobbe DR, Bassetti M, et al. Infections caused by KPCproducing Klebsiella pneumoniae: differences in therapy and mortality in a multicentre study. J Antimicrob Chemother. 2015;70(7):2133-43.

87.• Paul M, Daikos GL, Durante-Mangoni E, Yahav D, Carmeli Y, Benattar YD, et al. Colistin alone versus colistin plus meropenem for treatment of severe infections caused by carbapenem-resistant Gram-negative bacteria: an open-label, randomised controlled trial. Lancet Infect Dis. 2018;18(4):391-400 This is the largest randomized controlled trial of carbapenem-resistant Gramnegative bacterial infections to date, including $77 \% \mathrm{AB}$, and is the basis of recent limitations regarding carbapenempolymyxin combinations.

88. Dickstein Y, Lellouche J, Ben Dalak Amar M, Schwartz D, Nutman A, Daitch V, Yahav D, Leibovici L, Skiada A, Antoniadou A, Daikos GL, Andini R, Zampino R, DuranteMangoni E, Mouton JW, Friberg LE, Dishon Benattar Y, Bitterman R, Neuberger A, Carmeli Y, Paul M. 2018. Treatment Outcomes of Colistin- and Carbapenem-resistant Acinetobacter baumannii Infections: An Exploratory Subgroup Analysis of a Randomized Clinical Trial. Clinical Infectious Diseases 2019;69(5):769-776.

89. Jung SY, Lee SH, Lee SY, Yang S, Noh H, Chung EK, et al. Antimicrobials for the treatment of drug-resistant Acinetobacter baumannii pneumonia in critically ill patients: a systemic review and Bayesian network meta-analysis. Crit Care. 2017;21(1):319.

90. Kengkla K, Saokaew S, Kongpakwattana K, Chaiyakunapruk N, Apisarnthanarak A. Comparative efficacy and safety of treatment options for MDR and XDR Acinetobacter baumannii infections: a systematic review and network meta-analysis. J Antimicrob Chemother. 2017;73(1):22-32. 
91. Chen H, Liu Q, Chen Z, Li C. Efficacy of sulbactam for the treatment of Acinetobacter baumannii complex infection: a systematic review and meta-analysis. J Infect Chemother. 2017;23(5):278-85.

92. Jaruratanasirikul S, Wongpoowarak W, Wattanavijitkul T, Sukarnjanaset W, Samaeng M, Nawakitrangsan M, et al. Population pharmacokinetics and pharmacodynamics modeling to optimize dosage regimens of sulbactam in critically ill patients with severe sepsis caused by Acinetobacter baumannii. Antimicrob Agents Chemother. 2016;60(12):7236-44.

93. Clinical and Laboratory Standards Institute (CLSI). Performance standards for antimicrobial suscptibility testing. 29th edn. CLSI Supplement M100. Wayne PC, 2019.

94. Pouch SM, Patel G. Multidrug-resistant Gram-negative bacterial infections in solid organ transplant recipients - guidelines from the American Society of Transplantation Infectious Diseases Community of Practice. Clin Transpl. 2019;33:e13594.

95. Mazuski J, Tessier J, May A, Sawyer R, Nadler E, Rosengart M, et al. The Surgical Infection Society revised guidelines on the management of intra-abdominal infection. Surg Infect. 2017;18(1):1-76.

96. Hawkey J, Ascher DB, Judd LM, Wick RR, Kostoulias X, Cleland $\mathrm{H}$, et al. Evolution of carbapenem resistance in Acinetobacter baumannii during a prolonged infection. Microb Genom. 2018;4(3).

97. Guilhaumou R, Benaboud S, Bennis Y, Dahyot-Fizelier C, Dailly E, Gandia P, et al. Optimization of the treatment with beta-lactam antibiotics in critically ill patients - guidelines from the French Society of Pharmacology and Therapeutics (Société Française de Pharmacologie et Thérapeutique-SFPT) and the French Society of Anaesthesia and Intensive Care Medicine (Société Française d'Anesthésie et Réanimation — SFAR). Crit Care. 2019;23(1):104.

98. Katsube T, Wajima T, Ishibashi T, Arjona Ferreira JC, Echols R. Pharmacokinetic/pharmacodynamic modeling and simulation of cefiderocol, a parenteral siderophore cephalosporin, for dose adjustment based on renal function. Antimicrob Agents Chemother. 2017;61(1)

99. Zhanel GG, Golden AR, Zelenitsky S, Wiebe K, Lawrence CK, Adam HJ, et al. Cefiderocol: A siderophore cephalosporin with activity against carbapenem-resistant and multidrug-resistant Gram-negative bacilli. Drugs. 2019;79(3):271-89.

100. Portsmouth S, van Veenhuyzen D, Echols R, Machida M, Ferreira JCA, Ariyasu M, et al. Cefiderocol versus imipenem-cilastatin for the treatment of complicated urinary tract infections caused by Gram-negative uropathogens: a phase 2, randomised, double-blind, non-inferiority trial. Lancet Infect Dis. 2018;18(12):1319-28.

101. Shionogi, Shionogi I. Clinical study of S-649266 for the treatment of nosocomial pneumonia caused by Gram-negative pathogens 2019 [updated February 26. Available from: https:// ClinicalTrials.gov/show/NCT03032380. Accessed 20 Jun 2019.

102. Shionogi, Shionogi I. Study of S-649266 or best available therapy for the treatment of severe infections caused by carbapenemresistant Gram-negative pathogens 2019 [updated April 1. Available from: https://ClinicalTrials.gov/show/NCT02714595. Accessed 20 Jun 2019.

103. Durand-Reville TF, Guler S, Comita-Prevoir J, Chen B, Bifulco N, Huynh $\mathrm{H}$, et al. ETX2514 is a broad-spectrum beta-lactamase inhibitor for the treatment of drug-resistant Gram-negative bacteria including Acinetobacter baumannii. Nat Microbiol. 2017;2: 17104.

104. Lickliter J LK, O'Donnell J, Isaacs R. Safety and pharmacokinetics (PK) in humans of intravenous ETX2514, a $\beta$-lactamase inhibitor (BLI) which broadly inhibits Ambler class A, C, and D $\beta$ lactamases. Poster presented at 2017 IDWeek; 2017 Oct 3-8. San Diego, California, USA.
105. Zak-Doron Y, Dishon Benattar Y, Pfeffer I, Daikos GL, Skiada A, Antoniadou A, et al. The association between empirical antibiotic treatment and mortality in severe infections caused by carbapenem-resistant Gram-negative bacteria: a prospective study. Clin Infect Dis. 2018;67(12):1815-23.

106. Tsuji BT, Pogue JM, Zavascki AP, Paul M, Daikos GL, Forrest A, et al. International consensus guidelines for the optimal use of the polymyxins: endorsed by the American College of Clinical Pharmacy (ACCP), European Society of Clinical Microbiology and Infectious Diseases (ESCMID), Infectious Diseases Society of America (IDSA), International Society for Anti-infective Pharmacology (ISAP), Society of Critical Care Medicine (SCCM), and Society of Infectious Diseases Pharmacists (SIDP). Pharmacotherapy. 2019;39(1):10-39.

107. Hawkey PM, Warren RE, Livermore DM, McNulty CAM, Enoch DA, Otter JA, et al. Treatment of infections caused by multidrugresistant Gram-negative bacteria: report of the British Society for Antimicrobial Chemotherapy/Healthcare Infection Society/British Infection Association Joint Working Party $\dagger$. J Antimicrob Chemother. 2018;73(suppl_3):iii2-iii78.

108. Torres A, Niederman MS, Chastre J, Ewig S, FernandezVandellos P, Hanberger $\mathrm{H}$, et al. International ERS/ESICM/ ESCMID/ALAT guidelines for the management of hospitalacquired pneumonia and ventilator-associated pneumonia. Eur Respir J. 2017;50(3):1700582.

109. Wenzler E, Fraidenburg DR, Scardina T, Danziger LH. Inhaled antibiotics for Gram-negative respiratory infections. Clin Microbiol Rev. 2016;29(3):581-632.

110. Biagi M, Butler D, Tan X, Qasmieh S, Wenzler E. A breath of fresh air in the fog of antimicrobial resistance: inhaled polymyxins for Gram-negative pneumonia. Antibiotics (Basel, Switzerland). 2019;8(1).

111. Lenhard JR, Bulman ZP, Tsuji BT, Kaye KS. Shifting gears: the future of polymyxin antibiotics. Antibiotics. 2019;8(2):42.

112. Corbett D, Wise A, Langley T, Skinner K, Trimby E, Birchall S, et al. Potentiation of antibiotic activity by a novel cationic peptide: potency and spectrum of activity of SPR741. Antimicrob Agents Chemother. 2017;61(8):e00200-17.

113. Eckburg PB FN, Utley L, Walpole L, Keutzer T, Kopp E, Coleman S, Tomayko J. Safety of SPR741, a novel polymyxin potentiator, in healthy adults receiving single- and multiple-dose intravenous administrations. Poster presented at 28th European Congress of Clinical Microbiology and Infections Diseases; 2018 Apr 21-24; Madrid, Spain.

114. Liang CA, Lin YC, Lu PL, Chen HC, Chang HL, Sheu CC. Antibiotic strategies and clinical outcomes in critically ill patients with pneumonia caused by carbapenem-resistant Acinetobacter baumannii. Clin Microbiol Infect. 2018;24(8):908.e1-7.

115. Niu T, Luo Q, Li Y, Zhou Y, Yu W, Xiao Y. Comparison of tigecycline or cefoperazone/sulbactam therapy for bloodstream infection due to carbapenem-resistant Acinetobacter baumannii. Antimicrob Resist Infect Control. 2019;8(1):52.

116. Amat T, Gutierrez-Pizarraya A, Machuca I, Gracia-Ahufinger I, Perez-Nadales E, Torre-Gimenez A, et al. The combined use of tigecycline with high-dose colistin might not be associated with higher survival in critically ill patients with bacteraemia due to carbapenem-resistant Acinetobacter baumannii. Clin Microbiol Infect. 2018;24(6):630-4.

117. Zhou XP, Ye XJ, Shen JP, Lan JP, Jiang HF, Zhang J, et al. Salvage tigecycline in high risk febrile neutropenic patients with hematological malignancies: a prospective multicenter study. Leuk Lymphoma. 2018;59(11):2679-85.

118. Ni W, Han Y, Zhao J, Wei C, Cui J, Wang R, et al. Tigecycline treatment experience against multidrug-resistant Acinetobacter baumannii infections: a systematic review and meta-analysis. Int J Antimicrob Agents. 2016;47(2):107-16. 
119. Falagas ME, Vardakas KZ, Tsiveriotis KP, Triarides NA, Tansarli GS. Effectiveness and safety of high-dose tigecycline-containing regimens for the treatment of severe bacterial infections. Int $\mathrm{J}$ Antimicrob Agents. 2014;44(1):1-7.

120. Xu Y, Jin L, Liu N, Luo X, Dong D, Tang J, et al. Evaluation of the ratio of the estimated area under the concentration-time curve to minimum inhibitory concentration (estimated AUIC) as a predictor of the outcome for tigecycline treatment for pneumonia due to multidrug-resistant bacteria in an intensive care unit. Int J Infect Dis. 2019;82:79-85.

121. Ditch K NJ, Izmailyan S, Fyfe C, Tsai L. Microbiological efficacy of eravacycline against Enterobacteriaceae and Acinetobacter baumannii, including MDR isolates: a pooled analysis from IGNITE1 and IGNITE4, two phase 3 trials of complicated intraabdominal infection. Poster 629. Presented at 2018 ASM Microbe; 2018 June 7-11, Atlanta, GA, USA.

122. Pogue JM, Neelakanta A, Mynatt RP, Sharma S, Lephart P, Kaye KS. Carbapenem-resistance in gram-negative bacilli and intravenous minocycline: an antimicrobial stewardship approach at the Detroit Medical Center. Clin Infect Dis. 2014;59(Suppl 6):S38893.

123. Lashinsky JN, Henig O, Pogue JM, Kaye KS. Minocycline for the treatment of multidrug and extensively drug-resistant A. baumannii: a review. Infect Dis Ther. 2017;6(2):199-211.

124. Goff D, Bauer K, Mangino J. Bad bugs need old drugs: a stewardship program's evaluation of minocycline for multidrugresistant Acinetobacter baumannii infections. Clin Infect Dis. 2014;59(suppl_6):S381-S7.

125. Falagas ME, Skalidis T, Vardakas KZ, Voulgaris GL, Papanikolaou G, Legakis N. Activity of TP-6076 against carbapenem-resistant Acinetobacter baumannii isolates collected from inpatients in Greek hospitals. Int J Antimicrob Agents. 2018;52(2):269-71.

126. Newman J ZJ, Fyfe C, Weiss W, Pulse M. In vivo efficacy of TP6076 in murine thigh and lung infection models challenged with Acinetobacter baumannii. Poster presented at 29th European Congress of Clinical Microbiology and Infections Diseases; 2019 Apr 13-16; Amsterdam, Netherlands.

127. Tsai L MAS, Tolerability and pharmacokinetics of multiple doses of TP-6076, a novel, fully synthetic tetracycline, in a phase 1 study. Poster presented at 2019 ID Week; 2019 Oct 3-7; San Francisco, CA, USA.

128. Tetraphase Pharmaceuticals announces corporate reorganization aimed at maximizing XERAVA ${ }^{\mathrm{TM}}$ (Eravacycline) commercial opportunity [press release]. Business Wire, 12 Jun 2019.

129. Pfaller MA, Sader HS, Rhomberg PR, Flamm RK. In vitro activity of delafloxacin against contemporary bacterial pathogens from the United States and Europe, 2014. Antimicrob Agents Chemother. 2017;61(4)

130. Eljaaly K, Alharbi A, Alshehri S, Ortwine JK, Pogue JM. Plazomicin: A novel aminoglycoside for the treatment of resistant Gram-negative bacterial infections. Drugs. 2019;79(3):243-69.

131. Jorgensen SCJ, Mercuro NJ, Davis SL, Rybak MJ. Delafloxacin: place in therapy and review of microbiologic, clinical and pharmacologic properties. Infect Dis Ther. 2018;7(2):197-217.
132. Menegucci TC, Albiero J, Migliorini LB, Alves JL, Viana GF, Mazucheli J, et al. Strategies for the treatment of polymyxin Bresistant Acinetobacter baumannii infections. Int J Antimicrob Agents. 2016;47(5):380-5.

133. Kang AD, Smith KP, Eliopoulos GM, Berg AH, McCoy C, Kirby JE. In vitro apramycin activity against multidrug-resistant Acinetobacter baumannii and Pseudomonas aeruginosa. Diagn Microbiol Infect Dis. 2017;88(2):188-91.

134. Cisek AA, Dabrowska I, Gregorczyk KP, Wyzewski Z. Phage therapy in bacterial infections treatment: one hundred years after the discovery of bacteriophages. Curr Microbiol. 2017;74(2):27783.

135. Caflisch KM, Patel R. Implications of bacteriophage- and bacteriophage component-based therapies for the clinical microbiology laboratory. J Clin Microbiol. 2019.

136. Ho YH, Tseng CC, Wang LS, Chen YT, Ho GJ, Lin TY, et al. Application of bacteriophage-containing aerosol against nosocomial transmission of carbapenem-resistant Acinetobacter baumannii in an intensive care unit. PLoS One. 2016;11(12): e0168380.

137. Schooley RT, Biswas B, Gill JJ, Hernandez-Morales A, Lancaster $\mathrm{J}$, Lessor L, et al. Development and use of personalized bacteriophage-based therapeutic cocktails to treat a patient with a disseminated resistant Acinetobacter baumannii Infection. Antimicrob Agents Chemother. 2017;61(10).

138. LaVergne S, Hamilton T, Biswas B, Kumaraswamy M, Schooley RT, Wooten D. Phage Therapy for a multidrug-resistant Acinetobacter baumannii craniectomy site infection. Open Forum Infect Dis. 2018;5(4):ofy064.

139. Isler B, Doi Y, Bonomo RA, Paterson DL. New treatment options against carbapenem-resistant Acinetobacter baumannii infections. Antimicrob Agents Chemother. 2019;63(1):e01110-8.

140. Baginska N, Pichlak A, Gorski A, Jonczyk-Matysiak E. Specific and selective bacteriophages in the fight against multidrugresistant Acinetobacter baumannii. Virol Sin. 2019;34(4):347-57.

141. Motley MP, Fries BC. A new take on an old remedy: generating antibodies against multidrug-resistant Gram-negative bacteria in a postantibiotic world. mSphere. 2017;2(5):e00397-17.

142. Nielsen TB, Pantapalangkoor P, Luna BM, Bruhn KW, Yan J, Dekitani K, et al. Monoclonal antibody protects against Acinetobacter baumannii infection by enhancing bacterial clearance and evading sepsis. J Infect Dis. 2017;216(4):489-501.

143. Wang-Lin SX, Olson R, Beanan JM, MacDonald U, Russo TA, Balthasar JP. Antibody dependent enhancement of Acinetobacter baumannii infection in a mouse pneumonia model. J Pharmacol Exp Ther. 2019;368(3):475-89.

144. Evans BA, Amyes SG. OXA beta-lactamases. Clin Microbiol Rev. 2014;27(2):241-63.

145. Rhodes A, Evans LE, Alhazzani W, Levy MM, Antonelli M, Ferrer R, et al. Surviving sepsis campaign: international guidelines for management of sepsis and septic shock: 2016. Crit Care Med. 2017;45(3):486-552.

Publisher's Note Springer Nature remains neutral with regard to jurisdictional claims in published maps and institutional affiliations. 